\title{
Governança em segurança institucional: ferramenta estratégica para a geração de valor público da instituição
}

\section{Antonio Donizete Ferreira da Silva Rubens Parente Junior}

Tribunal Regional do Trabalho da $2^{\mathrm{a}}$ Região, São Paulo, SP - Brasil

O artigo aborda a governança e a gestão estratégica da segurança institucional na perspectiva da análise dos principais resultados voltados à geração de valor público, a partir da experiência no Tribunal Regional do Trabalho da $2^{a}$ Região. Discute-se a gestão e as ações da segurança institucional, de maneira a expor boas práticas que trazem reflexos positivos para o órgão no alcance de seus objetivos estratégicos e no cumprimento de sua missão institucional. Objetiva-se demonstrar como a atuação da segurança institucional pode gerar valor público à instituição, principalmente por meio da governança, gestão de processos e valorização das pessoas, o que faz da sua atuação uma importante ferramenta de efetividade da justiça. Como técnica de pesquisa, optou-se pela investigação bibliográfica e documental, com utilização do método dedutivo para apresentar conclusões. Após a avaliação das premissas, conclui-se que a governança da segurança institucional associada a boas práticas de gestão, com métodos permanentes e sistemáticos voltados à preservação da integridade das pessoas e do patrimônio, permite a identificação, a avaliação, o acompanhamento e a mitigação de ameaças à instituição, promovendo a independência e a imparcialidade da judicatura, o que promove maior acesso e efetividade da justiça, gerando valor público entregue à sociedade.

Palavras-chave: governança, segurança institucional, objetivos estratégicos 


\section{Gobernanza en seguridad institucional: herramienta estratégica para generar valor público de la institución}

El artículo aborda la gobernanza y la gestión estratégica de la seguridad institucional en la perspectiva de analizar los principales resultados destinados a generar valor público a partir de la experiencia del Tribunal Laboral Regional de la $2^{\mathrm{a}}$ Región. Se discuten las acciones y la gestión de la seguridad institucional para exponer las buenas prácticas que traen efectos positivos al organismo para alcanzar sus objetivos estratégicos y cumplir su misión institucional. El objetivo es demostrar cómo el desempeño de la seguridad institucional puede generar valor público para la institución, principalmente a través del gobierno, la gestión de procesos y la valoración de las personas, lo que hace de su desempeño una herramienta importante para la efectividad de la justicia. Como técnica de investigación, se eligió la investigación bibliográfica y documental, utilizando el método deductivo para presentar conclusiones. Después de evaluar las premisas, se concluye que la gobernanza de la seguridad institucional asociada con buenas prácticas de gestión, con métodos permanentes y sistemáticos destinados a preservar la integridad de las personas y los activos, permite la identificación, evaluación, monitoreo y mitigación de amenazas a la institución, promoviendo la independencia y la imparcialidad del poder judicial, lo que permite un mayor acceso y efectividad de la justicia, generando valor público entregado a la sociedad.

Palabras clave: gobernanza, seguridad institucional, objetivos estratégicos

\section{Governance in institutional security: strategic tool for generating public value in the institution}

The article addresses the governance and strategic management of institutional security in the perspective of analyzing the main results aimed at generating public value from the experience at the Regional Labor Court of the 2nd Region. Institutional security management and actions are discussed in order to expose good practices that bring positive effects to the body in reaching its strategic objectives and in fulfilling its institutional mission. The objective is to demonstrate how the performance of institutional security can generate public value for the institution, mainly through governance, process management and valuing people, which makes its performance an important tool for the effectiveness of justice. As a research technique, bibliographic and documentary research data were chosen, using the deductive method to present conclusions. After assessing the premises, it's been concluded that the governance of institutional security associated with good management practices, with permanent and systematic methods aimed at preserving the integrity of people and assets, allows the identification, evaluation, monitoring and mitigation threats to the institution, promoting the independence and impartiality of the judiciary, allowing greater access and effectiveness of justice, generating public value delivered to society.

Keywords: governance, institutional security, strategic objectives 


\section{Introdução}

A garantia de que as Casas de Justiça cumpram seu papel da pacificação social de forma eficiente, eficaz e efetiva decorre, direta ou indiretamente, da atuação da segurança institucional em muitos aspectos. As atividades de segurança institucional nos diversos órgãos públicos - em especial dentro do Poder Judiciário - buscam a produção e a salvaguarda de conhecimentos necessários à tomada de decisão, sendo assim uma ferramenta estratégica para a administração da justiça.

Partindo dessa premissa, o artigo objetiva demonstrar como a governança e as boas práticas de gestão da segurança institucional agregam valor público à instituição, principalmente pelos reflexos nos objetivos estratégicos alcançados a partir da experiência desenvolvida no Tribunal Regional do Trabalho da $2^{a}$ Região. Pretende-se ainda investigar como a governança aplicada à segurança institucional aperfeiçoa suas práticas e processos, apoiando o direcionamento, o controle e a avaliação das operações, ao mesmo tempo em que permite o acompanhamento da gestão dos recursos, com vistas à prestação de serviços mais eficientes, eficazes e efetivos.

Considerando que a governança pública e a gestão estratégica da segurança institucional - neste estudo também chamada de segurança judiciária - são essenciais a uma adequada organização administrativa e ao cumprimento da missão institucional, questiona-se como sua atuação, associada à cultura de governança, pode incrementar o valor público entregue pela instituição.

Para responder a esse questionamento, no primeiro tópico deste artigo serão analisados os conceitos relativos à governança pública e sua íntima relação com a gestão de processos afetos à segurança institucional dos órgãos públicos.

No segundo tópico abordar-se-á a estratégia como pilar fundamental da governança, onde será analisado o planejamento estratégico do Tribunal Regional do Trabalho da $2^{\text {a }}$ Região na perspectiva da segurança institucional, indicando-se o relacionamento e os reflexos dos resultados táticos e operacionais com os objetivos estratégicos institucionais.

$\mathrm{Na}$ terceira parte serão apresentadas as contribuições da segurança na geração de valor público na instituição, analisando-se alguns resultados das ações da segurança institucional no Tribunal Regional do Trabalho da $2^{\mathrm{a}}$ Região. 
Elegeu-se como técnica de pesquisa a investigação bibliográfica e documental e optou-se pelo método dedutivo para apresentar conclusões acerca do objeto de estudo, obtidas a partir de uma análise de premissas teóricas e de evidências empíricas.

A pesquisa se justifica pela relevância social e estratégica da segurança institucional no cenário nacional, contexto em que se buscam maneiras de aliar a cultura de governança com outras formas de contribuição, para que a prestação jurisdicional da instituição incremente o valor público entregue à sociedade.

No que se refere às questões de governança, os referenciais adotados foram os positivados no Guia da Política de Governança Pública do Governo Federal (BRASIL,2018) e nas publicações sobre governança do Tribunal de Contas da União. Nas questões afetas à segurança institucional, adere-se à visão de Marcelo Schettini, Hipólito Cardozo e Luciano Lopes (2018) para considerações a respeito do objeto.

\section{Governança: conceito e aplicação na atividade de segurança institucional}

A governança estabelece novos paradigmas para aprimorar o desempenho da administração pública e ajuda a enfrentar seu grande desafio em todas as esferas de poder: o de produzir resultados positivos e sustentáveis, com a maximização da qualidade dos serviços aliada à redução de custos organizacionais.

Os processos de gestão da estratégia e a formulação de indicadores de desempenho são exemplos de mecanismos essenciais às organizações públicas para que se definam metas e se mensurem os resultados alcançados. Não há como aferir resultados sem os subsídios técnicos e gerenciais necessários à definição da estratégia. Como afirma Deming (1989, p.190) ${ }^{1}$ : "Não se gerencia o que não se mede; não se mede o que não se define; não se define o que não se entende; não há sucesso no que não se gerencia".

Nesse cenário, a gestão do conhecimento para o alcance de resultados de uma organização pública passa necessariamente por uma política de governança bem definida e massificada dentro da instituição, para coordenar as ações de forma que a alta

\footnotetext{
1 William Edwards Deming, com sua afirmação, resumiu o que atualmente organizações públicas e privadas buscam para aprimorar seu desempenho: abordagem que se convencionou chamar de gestão por resultados. Por essa metodologia de gerenciamento, com base nas diretrizes da organização, têm-se as seguintes fases de gestão: a) traçar metas e objetivos estratégicos; b) medir e monitorar os resultados alcançados; c) confrontar e analisar o realizado x proposto; d) traçar planos de melhoria para atingir ou para superar o que foi inicialmente planejado.
} 
administração e os demais níveis de gestão obtenham ferramentas de mensuração do desenvolvimento organizacional. Assim, a definição de governança pública é essencial.

Governança, segundo o Banco Mundial em seu documento Governance and Development (1992, p.1), é “o exercício da autoridade, controle, administração, poder de governo" ". Em conceito mais abrangente e voltado à realidade brasileira, Martins e Marini (2014) definem governança pública como:

[...] um processo de geração de valor público a partir de determinadas capacidades e qualidades institucionais; da colaboração entre agentes públicos e privados na coprodução de serviços, políticas e bens públicos e da melhoria do desempenho. Dessa forma, nenhum desses elementos pode ser pensado de forma isolada. Governança pública é capacidade de governo; é governar em rede de forma colaborativa; é governar orientado para resultados; todos estes elementos juntos para gerar valor público sustentável. Fortalecer a capacidade de governo e governar em rede não faz sentido se não estiverem a serviço de resultados e da geração de valor público, que, por sua vez, não ocorrem de forma fortuita, mas demandam o desenvolvimento de capacidades e relacionamentos interinstitucionais (MARINI, 2014, p. 44).

\title{
No Brasil, o Guia da Política de Governança Pública do Governo Federal adota
}

o entendimento contido no Decreto $\mathrm{n}^{\circ}$ 9.203, de 22 de novembro de 2017: governança pública é o "conjunto de mecanismos de liderança, estratégia e controle postos em prática para avaliar, direcionar e monitorar a gestão, com vistas à condução de políticas públicas e à prestação de serviços de interesse da sociedade". Em outra definição, significa a profissionalização da tomada de decisão, materializada pelos resultados decorrentes da nova forma de gestão pública. Brainard Guy Peters ${ }^{3}$ afirma que:

\begin{abstract}
A boa governança é crucial para qualquer sociedade que deseje promover seu desenvolvimento econômico e o bem-estar de seu povo. No nível mais básico, governança significa a capacidade de estabelecer metas para a sociedade, bem como a capacidade de desenvolver programas que permitam atingir esses objetivos.
\end{abstract}

A afirmação traz a essência do significado da governança pública e apresenta a importância do estabelecimento de diretrizes e mecanismos para que os programas e as políticas públicas se efetivem na forma de valor agregado. A partir da adoção da abordagem gerencial na administração pública, o conceito de governança foi adaptado de forma a orientar a gestão por meio de políticas focadas em resultados perenes, dirigidas

\footnotetext{
2 Tradução nossa do original em inglês: a general definition of governance is the "exercise of authority, control, management, power of government".

3 O Professor Brainard Guy Peters, da Universidade de Columbia, inicia o prefácio do Guia da Política de Governança Pública do Governo Federal com a síntese da necessidade e da importância da governança para a administração pública. Afirma que sem uma boa governança, não é possível atingir os objetivos propostos para uma organização.
} 
e executadas de modo profissional, como se percebe em diversas iniciativas no Executivo, no Judiciário e no Legislativo.

O Programa Nacional de Gestão Pública e Desburocratização (GesPública) é o resultado da evolução histórica de uma série de iniciativas do Governo Federal para promover a gestão pública de excelência. O Programa trata a questão da governança como forma de promover a eficiência e a efetividade da administração. No Guia Referencial para Medição de Desempenho da Gestão ${ }^{4}$ (BRASIL, 2009), o tema é abordado pela seguinte perspectiva:

A Governança pública, por sua vez, baseia-se em múltiplos arranjos com a participação de diversos atores (estado, terceiro setor, mercado etc.) no desenvolvimento, na gestão de políticas públicas e no provimento de serviços. Este modelo não diminui a importância do estado, mas qualifica-o com o papel de orquestrador, direcionador estratégico, indutor e fomentador absolutamente essencial para a ativação e orientação das capacidades dos demais atores. Este paradigma promove a adoção de modelos de gestão pós ou neo-burocráticos, tais como: redes, modelos de gestão orgânicos (flexíveis, orientados para resultados, foco no beneficiário), mecanismos amplos de accountability, controle e permeabilidade (BRASIL, 2009, p.5 transcrição literal).

Diante de tal perspectiva, duas questões se destacam: a prestação de contas com responsabilização (accountability) e a transparência. Nesse sentido, Bingham, Nabatchi e O’Leary (2005) afirmam que a governança pública é um sistema que envolve não somente ferramentas, mas inclui processos que possibilitem a participação das pessoas, o que traz uma visão do cidadão como participante da gestão.

A aplicação do conceito de governança no nível das organizações é abordada no Referencial Básico de Governança Aplicável a Órgãos e Entidades da Administração Pública $^{5}$. Ali, o Tribunal de Contas da União faz um resgate histórico da governança pública analisada por diversos organismos internacionais, apresentando os ganhos que a boa governança permite, orientando as seguintes ações, em Brasil (2014, a):

\footnotetext{
${ }^{4}$ Trata-se de referencial metodológico que permitirá a governos (Federal, estaduais e municipais), áreas ou domínios de políticas públicas, conjuntos de organizações, organizações públicas e suas unidades definirem e mensurarem seu desempenho - assumindo-se que este é um primeiro e decisivo passo para a gestão do desempenho, possibilitando, em bases metodologicamente análogas, sua pactuação, avaliação e divulgação em momentos posteriores.

${ }^{5}$ O referencial é uma das mais importantes ferramentas para aperfeiçoamento da gestão dos órgãos públicos federais, inclusive do Poder Judiciário, que se fiam no guia para, em seu âmbito de competências, tratar questões de organização e gestão administrativa. A eficácia da administração da justiça revela-se como eficiência da prestação jurisdicional. Provas de que o Judiciário tem cada vez mais adotado políticas de governança são a constituição da Rede de Governança Colaborativa do Poder Judiciário; a implementação de plano estratégico em todos os tribunais; a edição dos relatórios Justiça em Números; entre outras iniciativas capitaneadas pelo Conselho Nacional de Justiça. Todas, em muitos aspectos, são orientadas pelos referenciais do Tribunal de Contas da União.
} 
a) garantir a entrega de benefícios econômicos, sociais e ambientais para os cidadãos;

b) garantir que a organização seja, e pareça, responsável para com os cidadãos;

c) ter clareza acerca de quais são os produtos e serviços efetivamente prestados para cidadãos e usuários, e manter o foco nesse propósito;

d) ser transparente, mantendo a sociedade informada acerca das decisões tomadas e dos riscos envolvidos;

e) possuir e utilizar informações de qualidade e mecanismos robustos de apoio às tomadas de decisão;

f) dialogar com e prestar contas à sociedade;

g) garantir a qualidade e a efetividade dos serviços prestados aos cidadãos;

h) promover o desenvolvimento contínuo da liderança e dos colaboradores;

i) definir claramente processos, papéis, responsabilidades e limites de poder e de autoridade;

j) institucionalizar estruturas adequadas de governança;

k) selecionar a liderança tendo por base aspectos como conhecimento, habilidades e atitudes (competências individuais);

1) avaliar o desempenho e a conformidade da organização e da liderança, mantendo um balanceamento adequado entre eles;

m) garantir a existência de um sistema efetivo de gestão de riscos;

n) utilizar-se de controles internos para manter os riscos em níveis adequados e aceitáveis;

o) controlar as finanças de forma atenta, robusta e responsável; e

p) prover aos cidadãos dados e informações de qualidade (confiáveis, tempestivas, relevantes e compreensíveis) (BRASIL, 2014 a, p. 14, grifo nosso).

Ainda segundo a publicação referencial, a governança no setor público pode ser analisada sob quatro perspectivas: (a) sociedade e Estado; (b) entes federativos, esferas de poder e políticas públicas; (c) órgãos e entidades; e (d) atividades intraorganizacionais. Todas estas, de forma sinérgica, propiciam controles e avanços necessários à consecução dos objetivos estratégicos da instituição, conforme Brasil (2014, a):

Enquanto a primeira define as regras e os princípios que orientam a atuação
dos agentes públicos e privados regidos pela Constituição e cria as condições
estruturais de administração e controle do Estado; a segunda se preocupa com
as políticas públicas e com as relações entre estruturas e setores, incluindo
diferentes esferas, poderes, níveis de governo e representantes da sociedade
civil organizada; a terceira garante que cada órgão ou entidade cumpra seu
papel; e a quarta reduz os riscos, otimiza os resultados e agrega valor aos
órgãos ou entidades (BRASIL, 2014 a, p. 22 , grifo nosso).

É pelas duas últimas perspectivas que as considerações deste trabalho se desenvolverão, apresentando as principais contribuições que as atividades de segurança institucional trazem para as organizações públicas em geral. Mais especificamente, para os tribunais brasileiros.

Ainda segundo a Corte de Contas, a perspectiva de órgãos e entidades "é a vertente corporativa da governança no setor público, com foco nas organizações (ANU, 2012), na 
manutenção de propósitos e na otimização dos resultados ofertados por elas aos cidadãos e aos usuários dos serviços (CIPFA, 2004)" (BRASIL, 2014 a, p. 22). Nessa perspectiva, a governança visa a garantir que as ações das organizações estejam alinhadas com o interesse público:

\begin{abstract}
Governança sob a perspectiva de atividades intraorganizacionais pode ser entendida como o sistema pelo qual os recursos de uma organização são dirigidos, controlados e avaliados.

Sob esta perspectiva, são analisados os processos decisórios, as estruturas específicas de governança e as relações intraorganizacionais, que visam, entre outras coisas, otimizar o uso de recursos, reduzir riscos e agregar valor a órgãos e entidades e contribuir para o alcance de resultados esperados por partes interessadas internas e externas à organização (BRASIL, 2014, a, grifo nosso
\end{abstract}

Tais conceitos passaram a ser aplicados aos tribunais brasileiros, principalmente após 2004, quando se alterou a Constituição Federal de 1988 pela Emenda Constitucional $n^{\circ} 45 / 2004^{6}$, que criou o Conselho Nacional de Justiça (CNJ), definindo-o como órgão responsável pelo estabelecimento da política nacional administrativa judiciária e pela governança judicial em sentido amplo. Na evolução do raciocínio, passamos a uma análise das funções e das operações no âmbito interno das organizações, que se relacionam em diversos níveis, impactando o desempenho da instituição.

Os conceitos até aqui apresentados trazem em si uma enormidade de atribuições, tarefas, ações e significado para o direcionamento estratégico de uma instituição, com o intuito de geração de valor público. No que compete ao setor de segurança institucional, tais atribuições, ações e procedimentos são plenamente aplicáveis.

Governança está relacionada com direção, estabelecimento de metas, coerência, implementação, responsabilização e avaliação. Nas palavras de Peters (2013, p. 29), “A raiz da palavra governança vem de um vocábulo grego que significa direção. Assim, logicamente o significado fundamental da governança é dirigir a economia e a sociedade visando objetivos coletivos". Nessa linha, os setores administrativos da instituição devem dirigir suas forças para atingir os objetivos comuns, ou seja, as atividades de suporte devem ter foco na atividade finalística do órgão, como forma de cumprir sua missão.

6 A CF/1988 passou a contar com o artigo 103-B, revelando a intenção do legislador de centralizar a governança no Judiciário ao instituir uma instância responsável pelo estabelecimento de políticas estruturais da administração judiciária, de modo a reconfigurar o exercício da magistratura à lógica gerencial moderna, adequando-se, por exemplo, o número de juízes à demanda processual e o emprego de padrões de produtividade e de desempenho. 
Assim é que o Tribunal de Contas da União vem realizando levantamentos sistemáticos para avaliar a governança em relação a algumas áreas específicas da gestão: pessoas, tecnologia da informação e comunicação, saúde, contratações, segurança pública etc. O Relatório do $2^{\circ}$ Levantamento de Governança e Gestão de Pessoas - ciclo 2016 traz o alinhamento entre governança e gestão de pessoas na administração pública federal, apresentando seus papéis e inter-relações (BRASIL, 2016):

\begin{abstract}
É importante fazer uma diferenciação entre governança e gestão, pois não são sinônimos, embora sejam complementares e interdependentes. De forma simplificada, pode-se dizer que governança se refere à definição do que deve ser executado (direcionamento), e gestão refere-se ao modo como se executa o que foi definido. [...]

Entende-se como governança de pessoas a aplicação de princípios e práticas de governança com enfoque na utilização desse recurso pelas organizações. Nesse sentido, adaptando-se o entendimento presente no art. $2^{\circ}$, II, da Resolução TCU 247/2011, pode-se conceituar governança de pessoas como o conjunto de diretrizes, estruturas organizacionais, processos e mecanismos de controle que visam a assegurar que as decisões e as ações relativas à gestão de pessoas estejam alinhadas às necessidades da organização, contribuindo para o alcance das suas metas (BRASIL, 2016, p. 9).
\end{abstract}

No caso do presente objeto de estudo, a aplicação por analogia desses conceitos nos parece lógica. A segurança institucional ${ }^{7}$ de um órgão é atividade de suporte, mas, sob diversos aspectos impacta na atividade finalística do órgão. No caso do Judiciário, quando atua na segurança dos oficiais de justiça e ajuda no cumprimento de mandados, a segurança institucional atua no processo judicial, como longa manus dos magistrados.

Indo além, pelas perspectivas tática e operacional, os responsáveis por gerir contratos da área de segurança, como vigilância terceirizada, de prevenção e combate a incêndio, bem como os relativos ao sistema de transporte, como gestão e renovação da frota de veículos e logística em geral, devem, obrigatoriamente, ater-se à missão maior da instituição e dirigir suas ações no sentido de responder a seguinte questão: como a atuação da minha área técnica pode ajudar na busca dos objetivos estratégicos da instituição?

Uma possível resposta é dada por Schettini et al. (2018), que afirmam:

7 Aquino (século XIII), definiu segurança como "ausência de risco, previsibilidade, a certeza quanto ao futuro". Segurança institucional, como a conhecemos hoje, tem origem na Roma antiga, onde já havia a chamada "separação dos poderes": o imperador e o Senado. Inicialmente, a "segurança" dos senadores era confiada aos pretorianos, guarda fiel ao imperador, cuja reputação de bons combatentes era tão grande quanto a fama de traição, por terem, inclusive, assassinado césares. Eram chamados de "o poder atrás do trono". Tal estrutura tinha a finalidade de preservar a independência dos poderes, mas, dadas as circunstâncias, o Senado não podia confiar a segurança de seus membros a guardas leais ao imperador, sob pena de morte em caso de discordância. Assim, o Senado romano passou a manter sua Guarda Senatorial, tida como a primeira "segurança institucional" regimentalmente formada e organizada. 
A relevância e o caráter estratégico da segurança institucional podem ser constatados considerando seu posicionamento hierárquico dentro dos órgãos. Geralmente, a segurança subordina-se à alta administração, de forma que medidas emergenciais ou urgentes possam ser resolvidas de forma célere e totalmente alinhadas ao desejo dos decisores (SCHETTINI; CARDOSO; LOPES, 2018, p. 13).

A gestão de processos de segurança institucional é complexa e requer alto grau de capacitação dos profissionais. O reconhecimento da importância da governança, como fundamental para a instituição e aplicável aos processos afetos à segurança institucional, faz com que as medidas adotadas sejam coerentes com os objetivos da instituição.

A normatização da atividade de segurança institucional, o estabelecimento de metas claras, compliance, accountability, gestão de contratos, capacitação em segurança e a execução das atribuições com economicidade são as expressões mais visíveis da governança aplicáveis à gestão da segurança institucional.

Essa perspectiva deve ser compreendida pelos gestores da área de segurança e pela alta administração, em todos os órgãos públicos, nos mesmos moldes do que apresenta o Gabinete de Segurança Institucional da Presidência da República (GSI), que, por meio da Portaria $^{\circ}$ 62, de 26 de junho de 2019, dispõe sobre o Comitê de Governança, Riscos e Controle do Gabinete de Segurança Institucional ${ }^{8}$. Tal portaria, em seu Art. $2^{\circ}$, apresenta um guia de governança da segurança institucional, que, com pequenas adaptações, aplicase a todos os órgãos públicos:

I - promover condutas e comportamentos condizentes com os padrões de ética e integridade aplicáveis ao setor público;

II - institucionalizar estruturas adequadas de governança, gestão de riscos e controles internos;

III - promover o desenvolvimento contínuo dos agentes públicos e incentivar a adoção de boas práticas de governança, gestão de riscos e controles internos;

IV - garantir a aderência às leis, regulamentos, códigos, normas e padrões, com vistas à condução das políticas e à prestação de serviços de interesse público;

V - promover a integração dos agentes responsáveis pela governança, pela gestão de riscos e pelos controles internos;

VI - promover a adoção de práticas que institucionalizem as responsabilidades dos agentes públicos na prestação de contas, na transparência e na efetividade das informações;

8 Em que pese a separação de poderes, boas práticas de gestão devem ser compartilhadas entre Executivo, Legislativo e Judiciário. Exemplo disso é que, em linha com a publicação exarada pelo Gabinete de Segurança Institucional da Presidência, o Tribunal Regional do Trabalho da $2^{\text {a }}$ Região publicou o Ato GP $n^{\circ}$ 29/2019, que institui a Secretaria de Segurança Institucional e estabelece ações no sentido da mudança de paradigma e da propagação da cultura de governança ao distribuir competências e criar procedimentos e normatizações. 
VII - aprovar políticas, diretrizes, metodologias e mecanismos para comunicação e institucionalização da gestão de riscos e dos controles internos;

VIII - supervisionar o mapeamento e a avaliação dos riscos chaves que possam comprometer a prestação de serviços de interesse público;

IX - liderar e supervisionar a institucionalização da gestão de riscos e dos controles internos, oferecendo suporte necessário para sua efetiva implementação no âmbito do Gabinete de Segurança Institucional da Presidência da República;

$\mathrm{X}$ - estabelecer limites de exposição a riscos globais do órgão, bem como os limites de escopo no nível de unidades ou atividades;

XI - aprovar e supervisionar método de priorização de temas e macroprocessos para gerenciamento de riscos e implementação dos controles internos da gestão;

XII - emitir recomendação para o aprimoramento da governança, da gestão de riscos e dos controles internos;

XIII - emitir recomendação para a criação de subcomitês no âmbito do Comitê de Riscos e Governança, com suas respectivas competências, em função das necessidades; e

XIV - monitorar as recomendações e orientações deliberadas pelo Comitê. XV - auxiliar a alta administração na implementação e na manutenção de processos, estruturas e mecanismos adequados à incorporação dos princípios e das diretrizes da governança previstos no Decreto $\mathrm{n}^{\circ} 9.203$, de 22 de novembro de 2017;

XVI - incentivar e promover iniciativas que busquem implementar o acompanhamento de resultados no órgão ou na entidade, que promovam soluções para melhoria do desempenho institucional ou que adotem instrumentos para o aprimoramento do processo decisório;

XVII - promover e acompanhar a implementação das medidas, dos mecanismos e das práticas organizacionais de governança definidos pelo Comitê Interministerial de Governança - CIG em seus manuais e em suas resoluções; e

XVIII - elaborar manifestação técnica relativa aos temas de sua competência.

Com base nesse referencial, as práticas de governança e gestão em segurança institucional se desenvolvem no âmbito do Tribunal Regional do Trabalho da $2^{\text {a }}$ Região. Componente importante e elo entre governança e gestão, a estratégia institucional é tema fundamental para a consecução da missão e o alcance das metas institucionais. Para o propósito da presente exploração é necessário compreender essa conexão.

\section{Estratégia: pilar fundamental para a governança}

Em linha com as orientações e os conceitos até aqui expostos, é importante observar que é da alta administração que emanam os principais direcionadores estratégicos do órgão. A governança tem como função, entre outras, avaliar as condições e o desempenho atual e futuro da organização, direcionando e orientando a elaboração de 
políticas e planos. A Figura 1, extraída do Referencial Básico de Governança Aplicável a Órgãos e Entidades da Administração Pública, demonstra a relação entre governança e gestão nas organizações.

\section{Figura 1 - Relação entre governança e gestão}
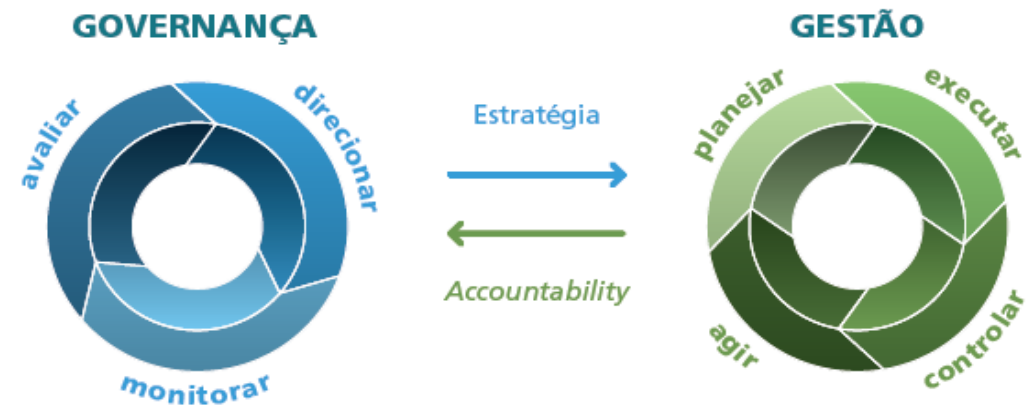

Fonte: BRASIL, Tribunal de Contas da União. Referencial Básico de Governança Aplicável a Órgãos e Entidades da Administração Pública, p.48

É pela estratégia que uma organização define sua identidade (missão, visão de futuro e valores) e estabelece os principais objetivos para o alcance dos resultados que entregarão valor público à sociedade. Assim, as organizações públicas têm na consecução de sua estratégia um pilar fundamental para a boa governança.

Cabe à gestão tática a execução e a coordenação operacional em áreas específicas (gestão de pessoas, tecnologia da informação e comunicação, orçamento e finanças, segurança institucional etc.). A gestão operacional, por sua vez, é diretamente responsável pela execução dos processos finalísticos e de apoio do órgão.

Nesse viés, a atuação da segurança institucional está vinculada à gestão estratégica, tática e operacional quando se avalia a questão dos riscos, como lembram Schettini et al. (2018):

\footnotetext{
O trabalho da segurança está diretamente relacionado com a gestão dos riscos - que são inerentes à atividade de salvaguarda de ativos. Isso faz com que o profissional de segurança esteja qualificado para compreender o processo de gestão de riscos, aplicá-lo e estabelecer parâmetros para o planejamento em segurança, de modo a nortear investimentos e alocação de recursos para este fim (SCHETTINI; CARDOSO; LOPES, 2018, p. 68).
}

Assim, a governança pelos prismas dos órgãos e entidades e das transações intraorganizacionais é diretamente impactada, a nosso ver, pelas inter-relações entre os três níveis organizacionais, pelo fluxo dos subsídios e resultados em duas vias: do fornecimento e do recebimento. A Figura 2 ilustra essa lógica. 


\section{Figura 2 - Relacionamentos da Gestão e Governança}

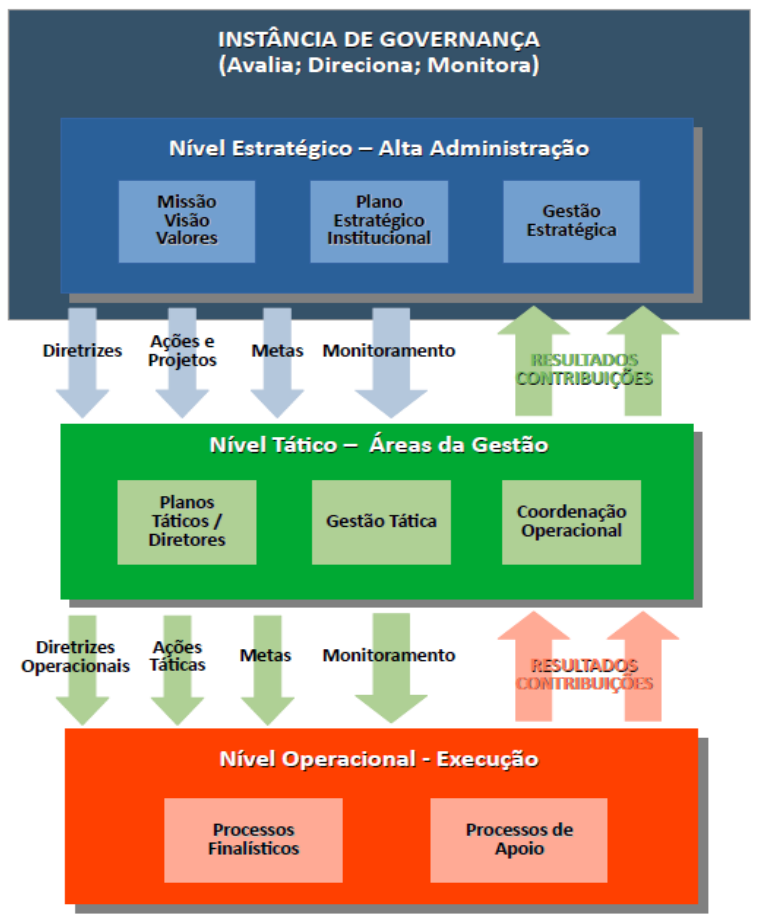

Fonte: Elaborada pelos autores.

A proposta da Figura 2 é apresentar a sinergia de atuação constante e demonstrar que a segurança institucional atua - ou deve atuar - nas três instâncias, na medida em que suas operações entregam resultados para os níveis tático e estratégico da instituição, como afirmam Schettini, Cardoso e Lopes (2018):

Uma vez feito todo processo de avaliação do risco, haverá subsídios necessários para a proposição de intervenções de modo a minimizar sua ocorrência. Essa etapa é chamada de Tratamento do Risco. O profissional de segurança irá considerar as análises realizadas para atuar na perspectiva de prevenir a ocorrência de situações que prejudiquem os ativos da instituição e/ou mitigar a probabilidade de que ocorram. Em ambos os casos a intervenção deve buscar minimizar as vulnerabilidades e, consequentemente, aumentar os pontos fortes da segurança (SCHETTINI; CARDOSO; LOPES, 2018, p. 77).

Essa sinergia constante de relacionamento, entre as próprias competências internas da segurança institucional e as entregas que realiza, denota sua importância estratégica, que ganha maior visibilidade quando se apresentam resultados mensuráveis ao longo de um ciclo e que, devidamente monitorados, podem apontar para boas práticas a serem replicáveis ou eventuais aperfeiçoamentos das ações.

\subsection{Estratégia no Poder Judiciário}

A cúpula administrativa do Judiciário brasileiro vem dando destaque ao planejamento e à gestão estratégicos, estabelecendo diretrizes e normas para o tema. 
Desde a edição pelo Conselho Nacional de Justiça (CNJ) da Resolução no 70/2009 (revogada pela Resolução 198/2014), o Poder Judiciário adotou como prática a formulação de planejamento estratégico, traçando objetivos e metas específicas.

São exemplos as várias iniciativas do colegiado, como a própria Resolução $\mathrm{n}^{\circ}$ 198/2014 e seus desdobramentos (planejamento estratégico do Judiciário e dos tribunais; encontros do Judiciário e as metas nacionais; metodologia de gestão estratégica etc.), que estabeleceu a Estratégia Nacional do Judiciário. Formulada com a contribuição de magistrados e servidores, reflete premissas importantes para o processo estratégico e aborda o assunto pelas perspectivas definidas em sua metodologia (sociedade; processos internos; e recursos), tratando-o conforme os resultados a serem entregues.

Como desdobramento direto da iniciativa do CNJ, o Conselho Superior da Justiça do Trabalho (CSJT) também vem adotando práticas nesse sentido, indicando os vetores para a regência estratégica e a gestão nas cortes trabalhistas do país.

A Estratégia da Justiça do Trabalho para o período 2015-2020 está definida na Resolução CSJT no 145, de 28 de novembro de 2014. Os objetivos e diretrizes ali estabelecidos guardam alinhamento em relação aos direcionadores nacionais, estabelecendo as definições gerais para o desenvolvimento da estratégia dos Tribunais Regionais do Trabalho.

\subsection{A Estratégia do Tribunal Regional do Trabalho da $2^{\mathrm{a}}$ Região}

Ao longo dos últimos anos, o Tribunal Regional do Trabalho da $2^{\mathrm{a}}$ Região vem buscando aprimorar suas práticas de governança e gestão estratégica. No exercício de reflexão pelo qual a instituição regularmente se debruça sobre os principais temas da gestão, é nítida a evolução da estratégia institucional quanto à preocupação com o estabelecimento de objetivos e metas que efetivamente aprimorem o papel social da instituição, incrementando de forma contínua o valor público entregue à sociedade.

O Tribunal deu seus primeiros passos na formulação estratégica em 2008, finalizando sua primeira versão do Plano Estratégico Institucional (PEI) em 2009. Em 2011 essa primeira versão foi revisada e adaptada à realidade então vigente. Em 2014, o Tribunal elaborou a versão 2015-2020, ainda em vigor.

Entre 2011 e 2014, foram muitas as realizações institucionais. Entre elas, podemos citar o aumento do acesso à justiça, com a instalação de 36 novas Varas do Trabalho e 
outras 16 Varas tipo Processo Judicial Eletrônico (PJe) ${ }^{9}$; aumento exponencial de acordos nas semanas de conciliação, com média de 20 mil audiências em cada semana; avanços no que se refere à responsabilidade socioambiental, como a instituição da Política Ambiental do Tribunal; entre outras medidas que visam à eficiência institucional e passaram a estabelecer diretrizes mais específicas por área.

A gestão estratégica também foi aperfeiçoada. Por exemplo, passaram a ocorrer reuniões de análise estratégica periódicas a partir de 2015, com acompanhamento da evolução das metas parciais por área, apresentando-se em cada reunião os resultados dos 24 indicadores. Com o estabelecimento do acompanhamento do PEI 2015-2020 de forma individualizada, ou seja, com relatórios executivos de indicadores parciais, os esforços foram canalizados para metas dirigidas por área de interesse, de forma que os resultados institucionais globais passaram a ser mais expressivos.

Após este início promissor, estabeleceu-se o Planejamento Estratégico Institucional - PEI 2015-2020, cujos aperfeiçoamentos em relação ao PEI anterior foram significativos. O Mapa Estratégico a seguir (Figura 3) resume a Estratégia Institucional do TRT da $2^{\text {a }}$ Região, para o período 2015-2020, alinhada aos direcionadores do CNJ e do CSJT.

\footnotetext{
${ }^{9}$ Varas onde os processos tramitam totalmente por meio eletrônico.
} 


\section{Figura 3 - Mapa Estratégico do TRT da $2^{\text {a }}$ Região}

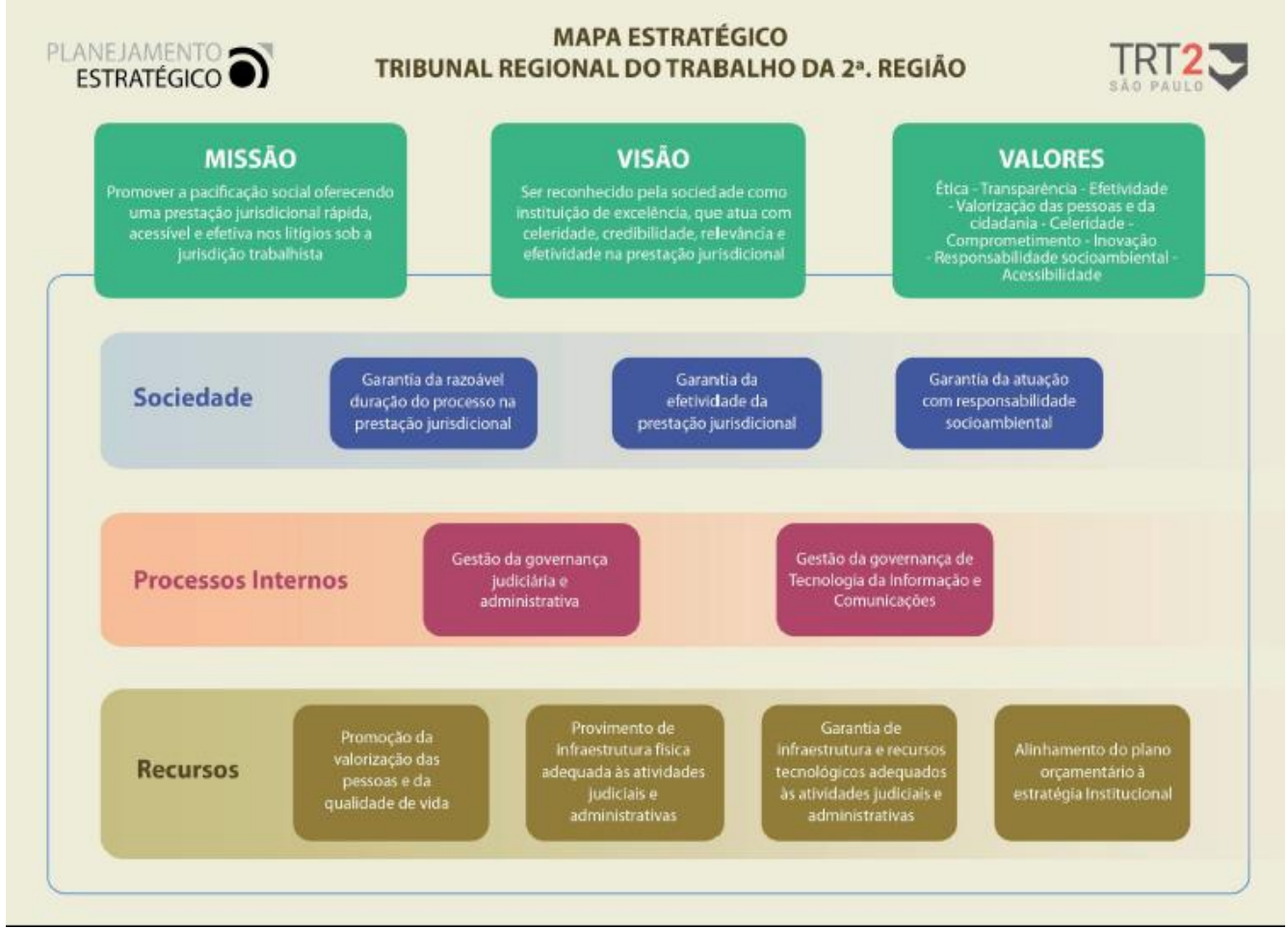

Fonte: disponível em https://ww2.trt2.jus.br/

A partir do PEI 2015-2020, o tribunal evoluiu em relação ao ciclo anterior no desdobramento tático da estratégia. Planos diretores foram elaborados, todos com seus objetivos e metas voltados ao atendimento da prescrição estratégica para o período. Estabeleceu-se o Plano Estratégico de Tecnologia da Informação e Comunicação (Petic); o Plano Diretor de Gestão de Pessoas (PDGP); o Plano Diretor de Tecnologia da Informação (PDTIC); o Plano de Logística Sustentável (PLS); e, mais recentemente, o Plano de Gestão de Riscos (PGR).

Dentro de cada área, foram criados comitês específicos que, em reuniões periódicas, monitoram metas e estabelecem um acompanhamento individualizado dos indicadores e dos resultados específicos. Considerando o iminente final do ciclo do PEI 2015-2020, desde janeiro está em preparação o Plano Estratégico da Justiça do Trabalho para o ciclo 2021-2026.

O TRT da $2^{\text {a }}$ Região, ante o aprendizado do ciclo 2015-2020 e em sintonia com as diretrizes do CSJT, publicou o Ato GP/VPA n 03/2019, que instituiu a Política de Governança, Gestão de Riscos e Compliance. A normativa tem como finalidade institucionalizar ações indutoras para o aprimoramento da gestão e da governança, garantindo um serviço de qualidade à sociedade. A norma orienta a atuação da instituição 
a partir de princípios como a efetividade, a transparência, a ética, a responsabilidade, a conformidade, a legitimidade e a inovação, estabelecendo como diretrizes o monitoramento do desempenho do órgão, o gerenciamento de riscos e a racionalização de processos. Tais ações são feitas por meio de reuniões trimestrais de acompanhamento, com a participação de todas as áreas, inclusive a Secretaria de Segurança Institucional.

Todavia, como o intuito deste estudo é o da apresentação das experiências relativas ao período 2015-2020, para efeito das reflexões que aqui consignamos, focamos em quatro objetivos estratégicos do PEI 2015-2020, nos quais há iniciativas e boas práticas do Tribunal implementadas pela segurança institucional:

Perspectiva Recursos - Objetivo 1. Promoção da valorização das pessoas e da qualidade de vida: compreende a promoção de políticas, métodos e práticas adotados na gestão de comportamentos internos, objetivando potencializar o capital humano na instituição, buscando a melhoria do clima organizacional, a valorização dos colaboradores e a humanização nas relações de trabalho. Visa à adequada aquisição de conhecimentos, habilidades e atitudes para o alcance dos objetivos institucionais, por meio do desenvolvimento e da gestão de competências tidas como essenciais.

\section{Perspectiva Recursos - Objetivo 2. Provimento de infraestrutura física} adequada às atividades judiciais e administrativas: trata-se de objetivo que almeja prover a instituição de recursos materiais (instalações, mobiliários, acesso) que permitam o bom desempenho das unidades, garantindo condições de trabalho que observem as peculiaridades do indivíduo, a preservação da saúde e a integridade física e mental das pessoas, frente aos riscos laborais e de segurança para o exercício das atividades.

\section{Perspectiva Processos Internos - Objetivo 5. Gestão da governança judiciária}

e administrativa: compreende a implantação e monitoramento da uniformização dos procedimentos e rotinas de atuação das unidades administrativas e judiciárias, garantindo que se alinhem ao planejamento estratégico e às metas da instituição. Propõe-se a adoção de modelos de gestão comprometidos com o fortalecimento da autonomia administrativa e financeira, com a transparência e com a proteção da coisa pública, visando à eficiência operacional e à probidade administrativa, incluindo gestão de processos de trabalho. 


\section{Perspectiva Sociedade - Objetivo 8. Garantia da efetividade na prestação}

jurisdicional: trata-se de objetivo que visa a garantir a entrega do bem da vida, solucionando problemas relativos ao acesso à justiça, à duração e ao custo do processo.

Como se percebe, os objetivos descritos nas três perspectivas mencionadas abarcam vários temas críticos para a gestão, ensejando diversas ações, muitas das quais complexas e profundas: gestão de comportamentos internos; acompanhamento e melhoria do clima organizacional; valorização das pessoas; humanização das relações de trabalho; gestão por competências; desenvolvimento profissional; promoção da saúde ocupacional; uniformização dos procedimentos e rotinas; adoção de modelos de gestão comprometidos com a transparência e com a proteção da coisa pública, visando à eficiência operacional e à probidade administrativa; estabelecimento das melhores práticas de comunicação da estratégia, de gestão documental, da informação, de processos de trabalho e de projetos, apenas para mencionar os principais.

Colocado o alinhamento conceitual e as bases para as reflexões que ora são propostas, passamos a um olhar mais direto sobre as contribuições que a governança e a gestão da segurança institucional trazem para o atingimento das metas do TRT da $2^{\text {a }}$ Região e, em sentido amplo, na geração de valor público da instituição.

\section{Segurança institucional: agregando valor à instituição}

Dada a natureza da atividade jurisdicional, que lida em essência com conflitos das mais variadas espécies, e diante do atual contexto social de violência urbana, associada à criminalidade organizada e à desestruturação das relações humanas, os magistrados brasileiros e seus auxiliares podem ficar expostos a riscos ou sofrer ameaças que, no mínimo, podem causar preocupação e afetar sua livre convicção ao prestar jurisdição. Nesse viés, a manutenção da sensação de segurança na instituição é condição sine qua non para que os magistrados exerçam seu mister com a imparcialidade e a independência necessárias.

Nesse sentido, Schettini e Silva (2019):

A segurança institucional, também chamada de segurança judiciária, há muito deixou de ser uma atividade secundária dentro da estrutura organizacional dos tribunais. Atualmente, diante do cenário de violência urbana, associada à criminalidade organizada e desestruturação das relações humanas, não se concebe deixar de considerar as ações de segurança institucional para a tomada das mais variadas decisões, principalmente dentro do Poder Judiciário, pois os magistrados e servidores, no exercício de suas atribuições, podem ficar expostos a riscos ou sofrer ameaças (SCHETTINI; SILVA, 2019, p. 258-259). 
Vão ao encontro dessa conclusão as disposições trazidas pelo Conselho Nacional

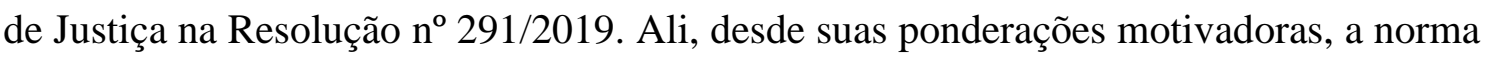
considera "que a segurança institucional é a primeira condição para garantir a independência dos órgãos judiciários, na forma dos arts. 10 da Declaração Universal dos Direitos Humanos; 14, 1, do Pacto Internacional dos Direitos Civis e Políticos; $2^{\circ}$ e $9^{\circ}$ do Código Ibero-Americano de Ética Judicial e $1^{\circ}$ do Código de Ética da Magistratura".

A estratégia do TRT da $2^{\text {a }}$ Região para o período 2015/2020 prevê três objetivos principais para a perspectiva da sociedade, dimensão na qual são produzidos os principais valores públicos ${ }^{10}$ entregues pela instituição. A missão da segurança institucional no âmbito do Poder Judiciário está estabelecida no art. $2^{\circ}$ da Resolução CNJ no 291/2019: "[...] promover condições adequadas de segurança pessoal e patrimonial, assim como meios de inteligência aptos a garantir aos magistrados e servidores da Justiça o pleno exercício de suas atribuições".

A partir das perspectivas dos recursos e dos processos internos, a consecução da estratégia institucional materializa os resultados necessários ao alcance dos objetivos na perspectiva da sociedade, conforme sintetiza a Figura 4:

\footnotetext{
${ }^{10} \mathrm{Na}$ forma como definidos pelo Guia para Elaboração na Forma de Relatório Integrado, relativo à Prestação de Contas - Relatório de Gestão 2019: “O Decreto 9.203/2017 sobre governança define valor público como sendo "produtos e resultados gerados, preservados ou entregues pelas atividades de uma organização que representem respostas efetivas e úteis às necessidades ou demandas de interesse público e modifiquem aspectos do conjunto da sociedade ou de alguns grupos específicos reconhecidos como destinatários legítimos de bens e serviços públicos". (BRASIL, 2019, p.11)
} 


\section{Figura 4 - Mapa de contribuições da segurança institucional}

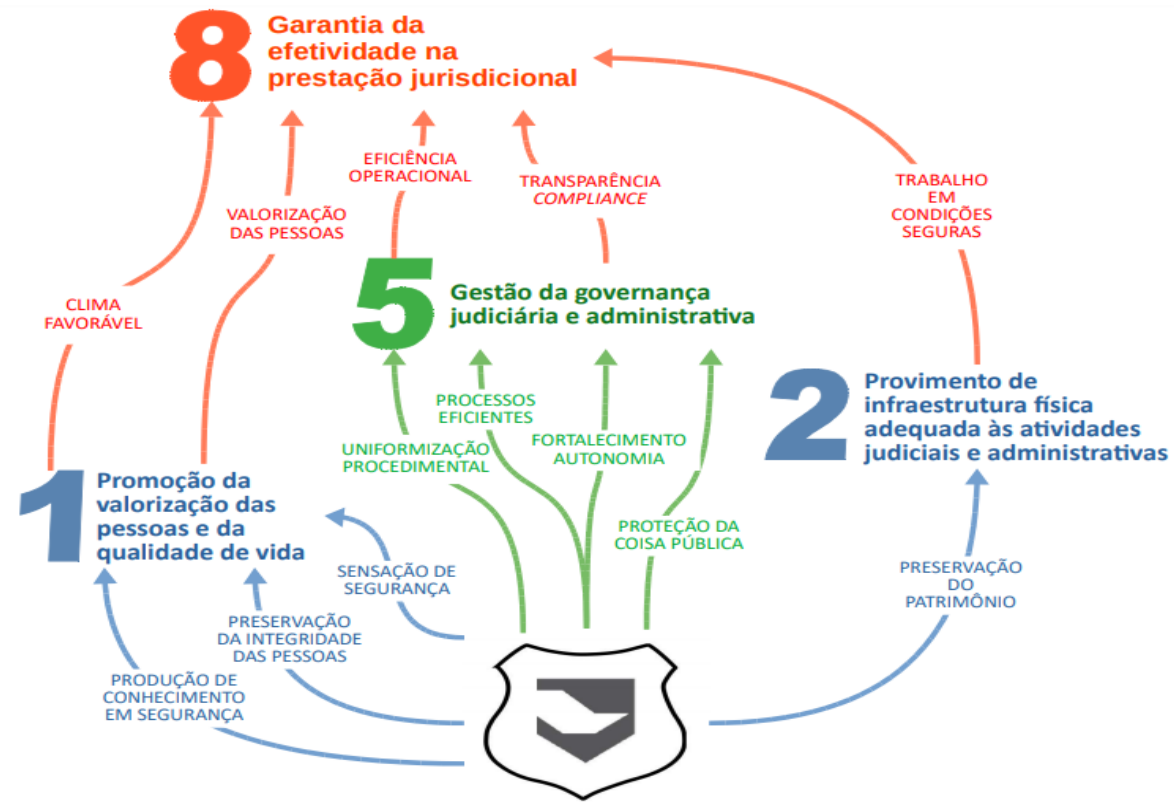

Fonte: Elaborada pelos autores.

A Secretaria de Segurança Institucional colabora para a entrega desse valor pela consecução dos objetivos 1 e 2, na perspectiva recursos; e 5, na perspectiva processos internos do PEI. Esses, por sua vez, impactam diretamente no objetivo 8: "Garantia da efetividade na prestação jurisdicional". Cada um dos vetores de atuação estratégica indicados aponta para o atendimento de um dos quatro objetivos estratégicos do Tribunal mais diretamente impactados pela segurança institucional, que assim contribui em seu âmbito de competências para o alcance das metas maiores da instituição, colaborando com os resultados mais complexos.

\subsection{Contribuições para o Objetivo Estratégico 1}

$\mathrm{Na}$ medida em que influencia comportamentos pela sensação de segurança proporcionada, a segurança institucional contribui para a melhora do clima organizacional, valoriza magistrados e servidores e humaniza as relações de trabalho. Também concorre para que as pessoas possuam conhecimentos, habilidades e atitudes para o alcance dos objetivos institucionais, por meio do desenvolvimento profissional.

Como termos comparativos para estabelecer a evolução entre os ciclos da gestão estratégica, no ano de 2013 a Secretaria de Segurança Institucional promoveu cursos para magistrados e para oficiais de justiça, capacitando 380 (trezentas e oitenta) pessoas. 
Diante dos resultados apresentados, no ciclo seguinte a quantidade de participantes aumentou, passando de 120 para 240 magistrados e de 260 para 400 oficiais de justiça em 2019. Esses dados expressam atualmente cerca de $50 \%$ e $90 \%$ dos quadros desses profissionais, respectivamente.

Em 2019, identificou-se a necessidade de capacitar as mulheres da instituição em cultura de segurança e de defesa pessoal, como forma de mitigar a violência contra a mulher. Em 2019, foram capacitadas 300 magistradas e servidoras do Tribunal. Essa iniciativa foi uma das mais bem avaliadas pelo público interno. Além de promover o conhecimento da cultura de segurança no âmbito institucional, estende hábitos seguros para a vida pessoal. O Gráfico 1 resume esses dados.

\section{Gráfico 1 - Ações de capacitação da segurança institucional}

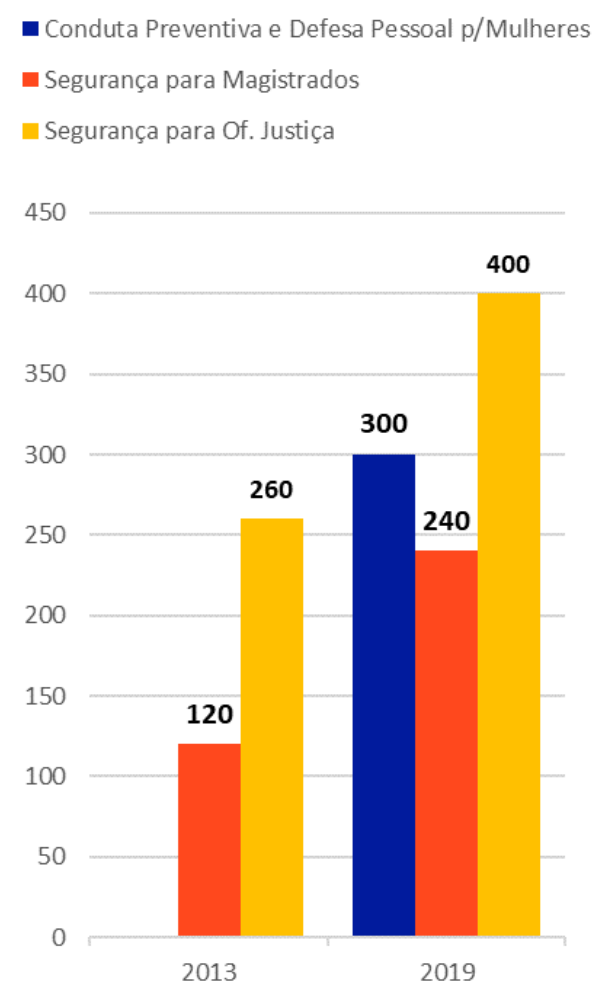

Fonte: Elaborado pelos autores.

As ações de capacitação promovidas pela área têm o objetivo de transmitir conhecimentos e aprimorar competências que incentivem comportamentos de prevenção e defesa. Essas ações geram outro impacto positivo, que pôde ser aferido pelo resultado da pesquisa de clima organizacional promovida no âmbito deste Regional em 2017 e 2019. 
O Gráfico 2 sintetiza os resultados relativos ao indicador segurança. Como forma de mensurar a sensação de segurança no órgão, o indicador se presta a avaliar se os procedimentos para entrar no prédio, o controle de acesso, a segurança das dependências e as condições de segurança pessoal são adequados.

\section{Gráfico 2 - Resultados da pesquisa de clima organizacional ${ }^{11}$}

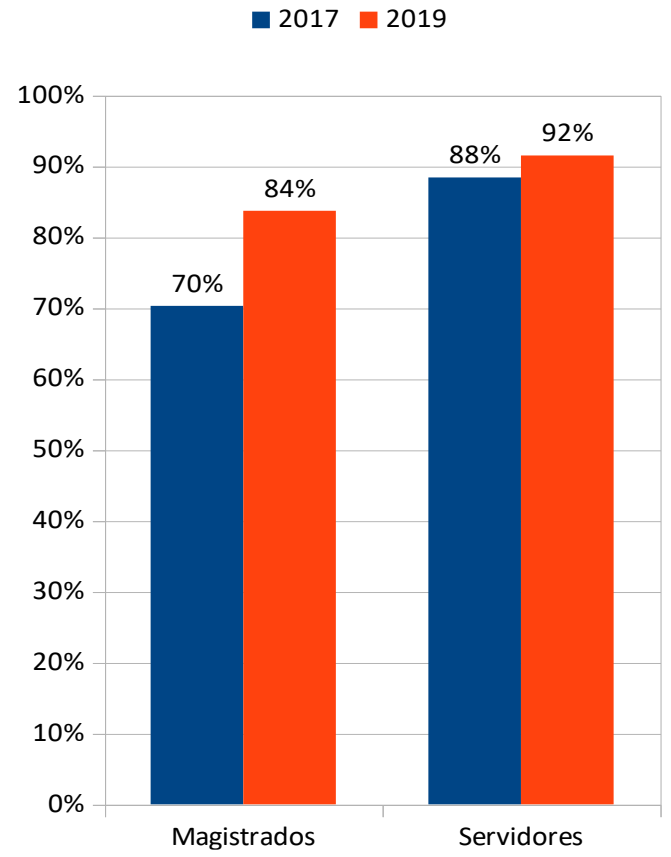

Fonte: Elaborado pelos autores.

Esses índices são obtidos pelo percentual de avaliações positivas em relação ao total de avaliações. Em 2019 o índice atingiu $92 \%$ de avaliações positivas entre servidores e 84\% entre magistrados. Os índices expressam um aumento de 14 pontos percentuais entre magistrados, o que demonstra o significativo incremento na sensação de segurança proporcionada.

Entre os servidores, o indicador expressa que 9 em cada 10 respondentes consideram que as condições de segurança são adequadas, nos vários aspectos, demonstrando que também entre os colaboradores a sensação de segurança é muito presente e as ações de segurança têm atingido os objetivos propostos.

11 Os resultados completos da pesquisa de clima organizacional estão disponíveis em: https://ww2.trt2.jus.br/transparencia/resultados-e-indicadores/relatorios/pesquisa-de-climaorganizacional/. 


\subsection{Contribuições para o Objetivo Estratégico 2}

A segurança institucional contribui para a consecução desse objetivo pela atuação para a preservação do patrimônio e dos recursos materiais da instituição (instalações, mobiliários, acesso), colaborando para o bom desempenho das unidades administrativas e judiciais. Ademais, age de forma relevante para mitigar riscos e ameaças à preservação da integridade física e mental de magistrados e servidores.

As atividades de segurança de áreas e instalações do órgão implicaram na detecção e prevenção de riscos e ameaças em todas as unidades do Regional. Como exemplo, destacamos os resultados das operações para controle de acesso, que detectaram e retiveram armas (acautelamento ${ }^{12}$ ) e outros objetos potencialmente ofensivos (apreensão). O Gráfico 3 demonstra a escala dos acautelamentos e apreensões que, caso não ocorressem, representariam risco potencial ao patrimônio e às pessoas.

Gráfico 3 - Acautelamento de armas e apreensão de objetos potencialmente ofensivos

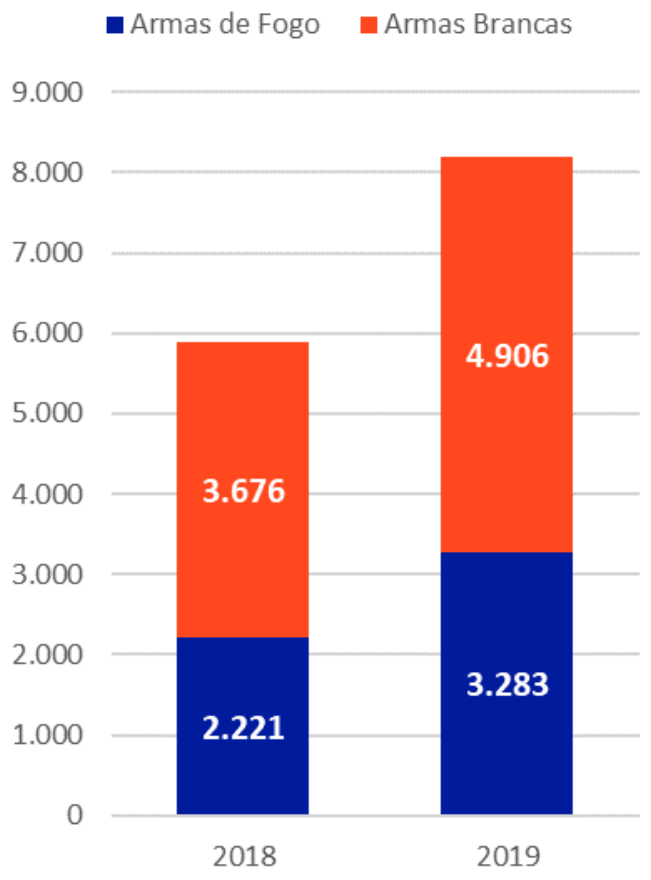

Fonte: Elaborado pelos autores.

12 Acautelamento, ou guarda, é a atividade desenvolvida pela segurança institucional em que um visitante que possua o porte de armas mantém seu equipamento em local apropriado (cofre) junto à área de segurança do Tribunal. A medida é necessária para evitar circulação de armas de fogo nas instalações do órgão. 
Em resumo, foram mais de 8 mil armas e outros objetos potencialmente ofensivos que foram retidos antes do ingresso nas instalações do órgão em 2019, mitigando assim potenciais ameaças a magistrados, servidores e demais frequentadores do Tribunal. Em relação a 2018, houve aumento de 47,8\% no acautelamento de armas de fogo e $33,5 \%$ na apreensão de objetos potencialmente ofensivos.

Ainda quanto à segurança de áreas e instalações, no exercício de 2019 a Secretaria de Segurança Institucional não mediu esforços para melhorar a eficiência das operações, sem perda da sua efetividade. Exemplo disso foi a economia gerada na transição dos contratos de alocação de mão de obra terceirizada com o incremento do monitoramento remoto e aperfeiçoamento do sistema de Circuito Fechado de TV (CFTV).

A instalação de novos equipamentos e a contratação de profissionais especializados para monitoramento remoto, aliada a uma nova estratégia de contratação de vigilância terceirizada, com a contratação por lotes, trouxe economia anual superior a dez milhões de reais em relação a 2019. Comparando-se com a média de 2014/2015, a redução é ainda maior. O Gráfico 4 sintetiza essa situação:

Gráfico 4 - Evolução da despesa com vigilância e monitoramento (R\$ milhões)

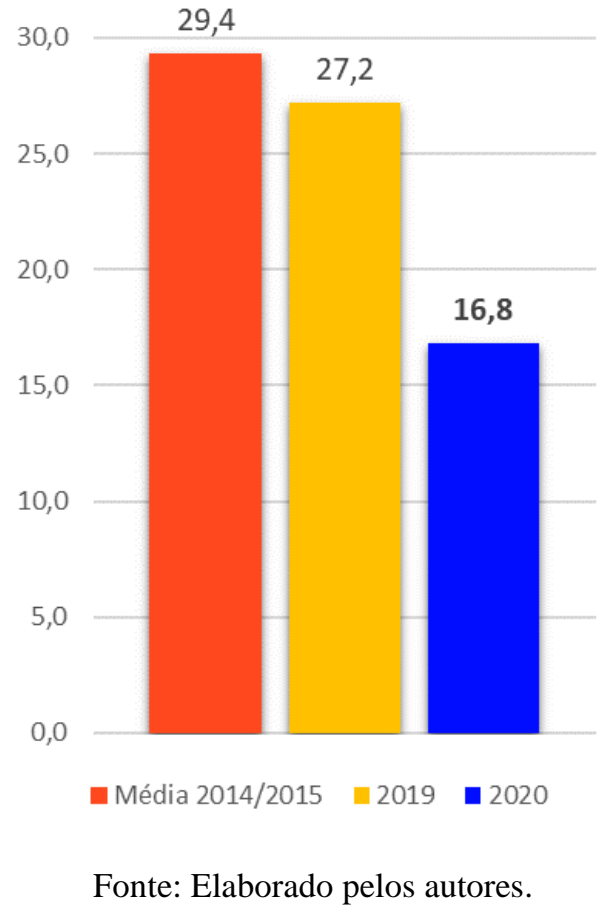




\subsection{Contribuições para o Objetivo Estratégico 5}

Governança e gestão pressupõem, antes de tudo, o entendimento das atividades que são realizadas como base para a definição dos vários subsistemas que as conformam. Essa inteligência constitui condição necessária para: a descrição de cargos e funções; a organização do trabalho; a definição de competências individuais e organizacionais; o estabelecimento de metas de desempenho; a formulação de políticas de desenvolvimento (capacitação); o planejamento da força de trabalho; entre outros. Todos eles mecanismos essenciais à regência estratégica da instituição.

A gestão por processos alicerça esse conhecimento. Para Davenport (1994, p.8), “Os processos são a estrutura pela qual uma organização faz o necessário para produzir valor para os seus clientes. Em consequência, uma importante medida de um processo é a satisfação do cliente com o produto desse processo". No setor público, isso fica ainda mais evidente, pois a eficiência, a prestação de contas e a transparência (três princípioschave da governança) precisam ser coordenados e assimilados pelos integrantes da "cadeia de valor"" . Neste sentido, Bruin (2007) afirma que o BPM tem por objetivo permitir às organizações meios de aperfeiçoar a forma como o trabalho (processos) é realizado, cujo foco é o alinhamento estratégico, eficiência e eficácia na geração de valor aos clientes.

Abordagem consagrada no mundo corporativo, o Business Process Management - BPM (Gerenciamento de Processos de Negócio) congrega práticas que permitem a melhor gestão das atividades do negócio da organização. O conjunto de conhecimentos no assunto mais adotado atualmente está reunido no $\mathrm{BPM} \mathrm{CBOK}^{\circledR}$ (Guia para Gerenciamento de Processos de Negócio - Corpo Comum de Conhecimento), organizado pela Association of Business Process Management Professionals (ABPMP).

A metodologia permite visão sistêmica da organização, pela descrição de seus processos de trabalho essenciais; suas dependências e inter-relações; a sequência lógica das atividades e seus requisitos; o dimensionamento de volumes e tempos de operação e, consequentemente, os requisitos profissionais e humanos para sua operação. Mais especificamente, duas de suas fases, o mapeamento e a análise dos processos, têm como

\footnotetext{
${ }^{13}$ Numa das primeiras abordagens sobre processos, Porter (1990) trabalhou a ideia de "cadeia de valor" (value chain), uma nova visão organizacional que foca uma estrutura baseada em atividades estrategicamente relevantes, que podem ser mensuradas a partir do valor que agregam aos processos.
} 
objetivo possibilitar essa inteligência. A Figura 5 resume os resultados esperados nessas duas etapas da abordagem por processos.

Figura 5 - Fases da abordagem por processos

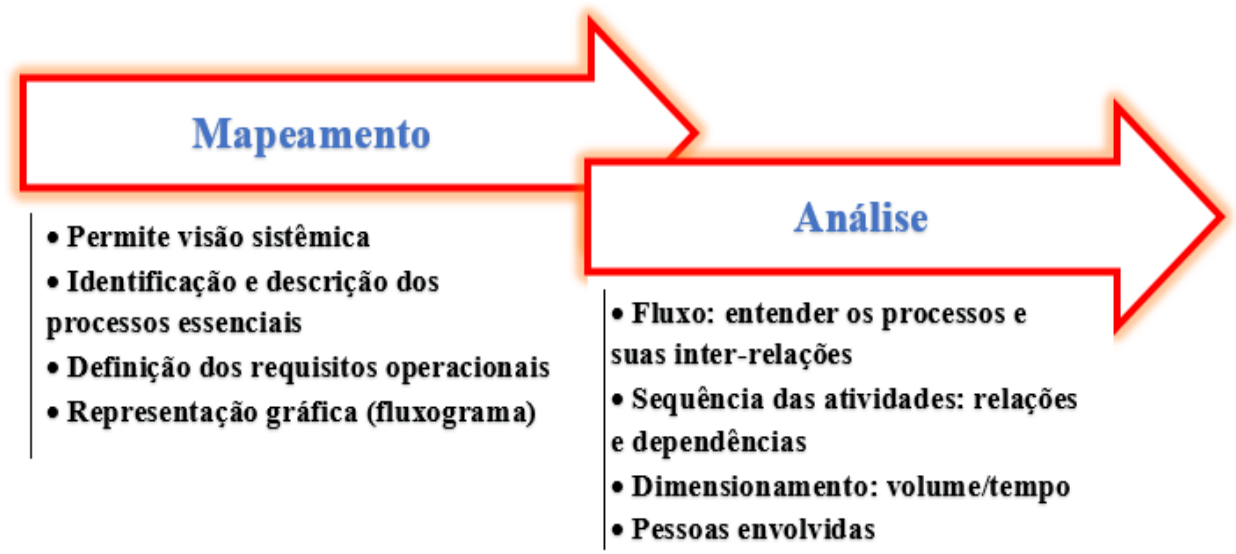

Fonte: Elaborado pelos autores

O Objetivo Estratégico 5 compreende a implantação, o monitoramento e a uniformização dos procedimentos e rotinas das unidades administrativas e judiciárias, garantindo que se alinhem ao planejamento estratégico e às metas da instituição. Mais ainda, a revisão procedimental emana do aprimoramento contínuo da governança institucional, na busca por eficiência, eficácia e efetividade. Nesse sentido, Domingues, Xavier e Birochi, (2015):

[...] a busca pela eficiência organizacional, por meio da melhoria dos processos, é o principal fator que impulsionou a decisão da alta administração adotar o BPM como ferramenta de gestão. Quer-se a otimização dos fluxos dos processos, a obtenção de dados que gerem informações e auxiliem a tomada de decisão e melhor controle organizacional (DOMINGUES; XAVIER; BIROCHI, 2015, p. 231)

Conforme o BPM CBOK, os processos da segurança institucional são considerados de suporte. Seu gerenciamento permite a realização das operações de forma alinhada e sistêmica em relação aos processos de negócio da instituição. As diversas contribuições estratégicas apresentadas neste artigo (sintetizadas na Figura 4), além de caracterizarem o impacto para a consecução dos objetivos institucionais, também configuram as inter-relações entre os processos da segurança e os demais da instituição.

Essa perspectiva é fundamental porque são comuns estruturas organizacionais construídas pelo enfoque hierárquico-funcional, nas quais a organização das unidades administrativas retrata a execução de "pedaços" dos processos, isoladamente. Essa segmentação acaba por fracionar a sequência lógica de agregação de valor, 
desconsiderando os requisitos necessários ao encadeamento operacional dos processos. O gerenciamento de processos tem como premissa fundamental a operação das atividades voltadas para a relação com o cliente. Assim, as expectativas (necessidades) de quem recebe o resultado do trabalho configuram os requisitos para quem vai produzi-lo.

Como forma de padronizar, consolidar e documentar as atividades da segurança institucional, o Regional adotou a iniciativa de elaborar um manual operacional, previsto no Ato GP no 29/2019, o qual, por meio da descrição de procedimentos operacionais padronizados e das ações esperadas - sempre orientados pela lógica e pelas inter-relações dos processos - permite a verificação de conformidade e o monitoramento constante das ações dos agentes de segurança. Consequência direta disso, o compromisso com a transparência e com a proteção da coisa pública será potencializado, alinhando ainda mais a atuação da área com a estratégia institucional, de forma a promover a eficiência operacional e a probidade administrativa.

\subsection{Contribuições para o Objetivo Estratégico 8}

Tal objetivo visa a garantir a entrega do bem da vida, solucionando problemas relativos ao acesso à justiça, à duração e ao custo do processo. De forma indireta, as contribuições para o alcance dos objetivos na perspectiva dos recursos criam condições para afastar, ou mesmo mitigar, riscos e ameaças que possam interferir na prestação jurisdicional trabalhista. De forma direta, as ações promovidas pela área contribuem para a efetividade da prestação jurisdicional pelas operações de:

- $\quad$ apoio ao cumprimento de diligências, colaborando para a eficácia e a eficiência da execução trabalhista, que, em muitos casos, somente foi possível devido ao apoio da segurança institucional;

- $\quad$ segurança de autoridades, na medida em que promovem a necessária sensação de segurança para que as autoridades judiciárias possam desempenhar seu mister com imparcialidade e independência, tanto no cotidiano da judicatura, quanto em eventos e outras atividades institucionais.

O Gráfico 5 demonstra a escala das operações dessa natureza realizadas nos exercícios de 2018 e de 2019, quando tais ações foram institucionalizadas: 


\section{Gráfico 5 - Segurança de autoridades e acompanhamento de diligências - número de operações}

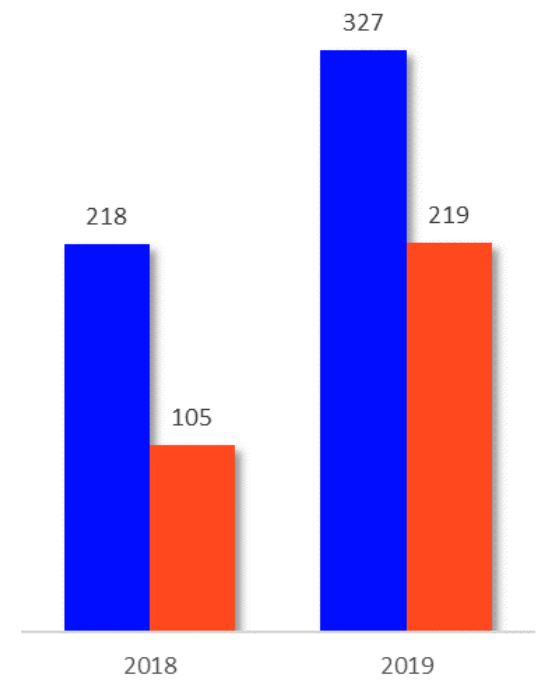

Fonte: elaboração pelos autores.

Também contribuem significativamente para a efetividade da prestação jurisdicional as atividades de inteligência, que compreendem o exercício permanente e sistemático de ações especializadas para identificar, avaliar e acompanhar ameaças reais ou potenciais aos ativos do Poder Judiciário, orientadas para a produção e salvaguarda de conhecimentos necessários ao processo decisório no âmbito institucional.

Ou seja, a segurança institucional é importante gerador de valor público, seja de forma direta ou indireta. Sua atuação proporciona meios para a organização aperfeiçoar ações e cumprir metas, melhorando resultados e dando maior efetividade à prestação jurisdicional. Em última análise, garante o acesso à justiça em sentido material.

\section{Conclusões}

O termo governança pública nasce para permitir o exercício do "poder" por parte da sociedade. Apresenta-se na forma como as organizações são administradas, dirigidas e controladas. Refere-se a mecanismos ou princípios que governam o processo decisório em uma organização. Seus processos, procedimentos e regras objetivam minimizar problemas e dar maior eficiência ao sistema.

Compreender a governança é função básica para se gerir uma instituição, pois é dela que emanam os direcionadores para o planejamento e a gestão das organizações públicas. Para que a governança seja efetiva e assegure resultados é essencial que haja coordenação e monitoramento da gestão, conforme a estratégia e as ações prescritas, 
especialmente quanto à implementação, à responsabilização, à mensuração e avaliação de resultados, sempre atrelados a metas coerentes, mensuráveis e factíveis.

A segurança institucional faz parte do conjunto sistêmico e interdependente de operações institucionais e suas ações estão intimamente ligadas aos resultados da organização. O Manual de Operações da área, orientado pelo gerenciamento dos processos, associado à publicação de normativos próprios, trazem princípios, metas concretas e procedimentos auditáveis e transparentes. Em conjunto com mecanismos de controle periódico, como reuniões dos comitês gestores das áreas, capacitações de gestores, bem como, atuação na fase de execução processual e o monitoramento das ações desenvolvidas pela segurança institucional, agem em harmonia com os demais esforços institucionais para o cumprimento da missão do Tribunal.

A segurança institucional deve ser percebida como agregadora de valor público, posto que hoje não tem enfoque apenas na proteção dos indivíduos e seu patrimônio. Exerce papel estratégico fundamental na medida em que impacta positivamente o clima organizacional, a valorização das pessoas, o desenvolvimento profissional e a uniformização dos procedimentos. Aperfeiçoando e uniformizando seus processos, colabora na adoção de modelos de gestão comprometidos com a transparência e com a proteção da coisa pública, visando à eficiência operacional e à probidade administrativa.

A autuação da segurança institucional é sintetizada na Figura 4 e revela os caminhos para o atingimento dos objetivos estratégicos da organização. Tais vetores de atuação configuram ações estratégicas que, concretizadas, demonstram os avanços da área, mas também identificam eventuais aspectos de melhoria para os ciclos subsequentes. É esse monitoramento constante, coerente e dedicado, com direcionamento e padronização adequados, que transforma uma função tida como assessória (no caso, a segurança) em uma renovada e importante ferramenta estratégica.

A governança associada a boas práticas de gestão da segurança, com métodos permanentes e sistemáticos, permite que se identifique, avalie e sejam acompanhadas ameaças à instituição, promovendo assim a independência e a imparcialidade do judiciário, gerando, ainda, maior acesso e efetividade da justiça, principalmente quando atua na fase de execução processual e ajuda a entregar o "bem da vida" ao jurisdicionado.

Os estudos e as ações para aperfeiçoamento da governança e da gestão da segurança institucional certamente continuarão no âmbito do TRT da $2^{\mathrm{a}}$ Região, principalmente porque as ações sempre carecem de desenvolvimento devido às naturais 
mudanças sociais em busca de maior efetividade das ações e da geração de valor público.

\section{Referências}

BINGHAM, Lisa Blomgren; NABATCHI, Tina; O'LEARY, Rosemary. New Governance: practices and processes for stakeholder and citizen participation in the work of Government. Public Administration Review, v. 65, n. 5, p. 547558, 2005. Disponível em: https://onlinelibrary.wiley.com/doi/abs/10.1111/ j.1540-6210.2005.00482.x. Acesso em: $19 / 02 / 2020$.

BRASIL. Casa Civil da Presidência da República. Ministério da Fazenda (MF). Ministério do Planejamento Desenvolvimento e Gestão (MP). Ministério da Transparência e ControladoriaGeral da União (CGU). Guia da Política da Governança Pública. Brasília - DF, 2018. Disponível em http://www.casacivil.gov.br/governanca/guia/gu ia/prefaciola. Acesso em: 19/02/2020.

Tribunal de Contas da União. Referencial Básico de Governança Aplicável a Órgãos e Entidades da Administração Pública. Versão 2. Brasília: TCU, Secretaria de Planejamento, Governança e Gestão, 2014. Disponível em: https://portal.tcu.gov.br/governanca/governanca publica/organizacional/referencias/. Acesso em: $15 / 02 / 2020$.

Decreto $n^{\circ} 9.203$, de 22 de novembro de 2017. Brasília, 2017. DOU de 23/11/2017. Disponível em: http://www.planalto.gov.br/ccivil_03/_ato20152018/2017/decreto/D9203.htm. Acesso em $21 / 02 / 2020$

Ministério do Planejamento, Orçamento e Gestão. Secretaria de Gestão. Guia referencial para medição de desempenho e manual para construção de indicadores. Brasília, DF, 2009. Disponível em

http://www.gespublica.gov.br/content/guiareferencial-para-medi\%C3\%A7\%C3\%A3o-dedesempenho-e-manual-paraconstru\%C3\%A7\%C3\%A3o-de-indicadores Acesso em: 15/02/2020.

Gabinete de Segurança Institucional da Presidência da República. Portaria $n^{\circ}$ 62, de 26 de junho de 2019. Dispõe sobre o Comitê de Governança, Riscos e Controle do Gabinete de Segurança Institucional da Presidência da
República. DOU de 28/06/2019, Ed. 123, Seção1, p. 35. Brasília-DF, 2019.

Tribunal Regional do Trabalho da $2^{\mathrm{a}}$ Região. Ato GP no 29, de 28 de junho de 2019. Institui a Secretaria de Segurança Institucional do Tribunal Regional do Trabalho da $2^{\mathrm{a}}$ Região e dá outras providências. DeJT - CAD. ADM. 05/07/2019. São Paulo, 2019. Disponível em: http://www.trtsp.jus.br/leg-normas-atos-norm. Acesso em: 21/02/2020.

Tribunal Regional do Trabalho da $2^{\mathrm{a}}$ Região. ATO GP/VPA $n^{\circ}$ 03/2019. Institui a Política de Governança, Gestão de Riscos e Compliance no âmbito do Tribunal Regional do Trabalho da $2^{\mathrm{a}}$ Região. Disponível em: http://www.trtsp.jus.br/geral/tribunal2/Normas Presid/Atos/2019/GP VPA 03 19.html Acesso em: 23/02/2020.

Conselho Nacional de Justiça. Resolução $n^{o}$ 291, de 23 de agosto de 2019. Consolida as Resoluções do Conselho Nacional de Justiça sobre a Política e o Sistema Nacional de Segurança do Poder Judiciário e dá outras providências. DJe/CNJ no 179/2019, de 30/08/2019, p. 5-7. Brasília-DF, 2019. Disponível em: https://atos.cnj.jus.br/files/resolucao_291_2308 2019_02092019175339.pdf. Acesso em: $25 / 02 / 2020$

Conselho Nacional de Justiça. Resolução $n^{\circ} 198$, de $1^{\circ}$ de julho de 2014. Dispõe sobre o Planejamento e a Gestão Estratégica no âmbito do Poder Judiciário e dá outras providências. DJE/CNJ $n^{\circ} 114$, de 3/07/2014, p.4-7; 16-19. Brasília-DF, 2014. Disponível em: https://atos.cnj.jus.br/files/resolucao_198_0107 2014 30052019152048.pdf. Acesso em: 25/02/2020

Conselho Superior da Justiça do Trabalho. Resolução $n^{\circ} 145$, de 28 de novembro de 2014. Aprova o Plano Estratégico da Justiça do Trabalho para o período de 2015 a 2020 e dá outras providências. Diário Eletrônico da Justiça do Trabalho, Brasília-DF, n. 1615, 2 dez. 2014. Caderno Administrativo [do] Conselho Superior da Justiça do Trabalho, p. 2-3. Brasília-DF, 2014. Disponível em: https://juslaboris.tst.jus.br/bitstream/handle/20.5 
00.12178/53283/2014_res0145_csjt.pdf?sequen ce $=6 \&$ isAllowed $=y$. Acesso em: 25/02/2020.

Tribunal de Constas da União. Relatório do $2^{\circ}$ Levantamento de Governança e Gestão de Pessoas - ciclo 2016. Brasília-DF, 2016. Disponível em

https://portal.tcu.gov.br/secretaria-de-

fiscalizacao-de-pessoal/perfil-de-governancade-pessoas/. Acesso em: 21/02/2020.

BResSER PereIRA, Luiz C. Uma nova gestão para um novo estado: liberal, social e republicano. Revista do Serviço Público, v. 52, n. 1, p. 5-24, 2001. Disponível em: https://revista.enap.gov.br/index.php/RSP/articl e/view/298/304. Acesso em: 20/02/2020.

BRUIN, T. Insights into the evolution of BPM in rganisations. $18^{\circ}$ Australasian Conference on Information Systems, Toowoomba, Dec 2007. Disponível em: https://aisel.aisnet.org/cgi/viewcontent.cgi?articl $\mathrm{e}=1047 \&$ context $=$ acis2007 Acesso em: $22 / 02 / 2020$

DAVENPORT, Thomas H. Reengenharia de processos: como inovar na empresa através da tecnologia da informação. 5. ed. Rio de Janeiro: Campus, 1994.

Deming, W. Edwards. O método Deming de administração. 5. ed. São Paulo: Marques Saraiva, 1989.

DOMINGUES, Flavia de M. F. V.; XAVIER, Wlamir G.; BIROCHI, Renê. Gestão por processos: uma análise da ferramenta de gestão utilizada no Poder Judiciário de Santa Catarina. Revista Eletrônica de Estratégia \& Negócios, Florianópolis, v.8, n.1, p. 199-238, jan./abr.
$2015 . \quad$ Disponível em: http://portaldeperiodicos.unisul.br/index.php/Ee N/article/view/2806. Acesso em: 13/07/2020.

MARTINS, Humberto Falcão; MARINI, Caio. Governança pública contemporânea: uma tentativa de dissecação conceitual. Revista do Tribunal de Contas da União, v. 46, n. 130, p. 42-53, maio/agosto 2014. Disponível em: https://revista.tcu.gov.br/ojs/index.php/RTCU/is sue/view/8. Acesso em: 19/02/2020PETERS, Brainad Guy. O que é governança? Revista do $T C U$, n. 127, p. 28-33, maio/ago. 2013.

SCHETTINI, Marcelo; CARdoso, Hipólito Alves; LOPES, Luciano Santana. Segurança institucional no serviço público: aspectos técnicos e administrativos aplicáveis à segurança dos órgãos públicos brasileiros. 2. ed. São Paulo: Fontenele Publicações, 2018.

SchetTini, Marcelo; Silva, Antonio Donizete Ferreira. Inteligência e sua atuação nos Núcleos de Pesquisa Patrimonial e Segurança Judiciária. Revista do Tribunal Superior do Trabalho, São Paulo, v. 85, n. 3, p. 251-270, jul/set 2019.

WORLD BANK. The International Bank for Reconstruction and Development (IBDR). International Development Association (IDA). Governance and development. Washington D.C., $1992 . \quad$ Disponível em: http://documents.worldbank.org/curated/pt/6049 51468739447676/Governance-anddevelopment. Acesso em: 20/02/2020.

PORTER, M. E. The competitive advantage: creating and sustaining superior performance. Nova York: Free Press, 1985. (Republicado com nova introdução, 1998.)

\section{Antônio Donizete Ferreira da Silva}

\section{iD https://orcid.org/0000-0003-4962-0246}

Doutorando em Administração na Universidade Nove de Julho/SP. Mestre em Direito (2018). MBA em Gerenciamento de Crises (2019). Especialização em Direito e Processo do Trabalho (2017). Graduado em Direito (2015).

E-mail: antonio.donizete@ trtsp.jus.br

\section{Rubens Parente Junior}

\section{iD https://orcid.org/0000-0002-7257-5060}

Especialista em Gestão de Pessoas - Liderança, Carreiras e Coaching, pela Pontifícia Universidade Católica/RS (2020). Bacharel em Gestão de Recursos Humanos, pelo Centro Universitário Claretiano (2010).

E-mail: rubens.parente@trtsp.jus.br 